\title{
A New Harmonic Polyhedral Structure Based in Life and Well-Being as Framework to Solve the Main Problem of the Sustainable Development
}

\author{
Juan Ángel Chica-Urzola ${ }^{1}$, Ciro Alfonso Serna Mendoza ${ }^{2}$
}

\begin{abstract}
Since its appearance in the 70s of the last century, Sustainable Development (SD) as a concept has had multiple definitions making this something that is considered still under construction. This situation has made the SD has become a problem of permanent discussion and multiple interpretations. As each new concept addresses a different element to develop and sustain, the variables, indicators, measurement, interpretation and improvement strategies vary, even making it impossible to reproduce the measurement of it or its inapplicability in different territories. A concept of SD based on a harmonized structure and founded on the well-being of the individual and the society in which it is immersed, becomes the key to overcome this problem that has even led to the deviation and indiscriminate use of the term "Sustainable" and of the SD itself. This concept of SD must respond to a polyhedral structure in which both the main or base plan and the fundamental or improvement axis are associated with life and well-being, which implies the undeniable and indissoluble existence of a fundamental relationship between the DS and Welfare and more in depth, between the development of the individual and social development.
\end{abstract}

Keywords: Sustainable Development, Well-Being, Harmonic Polyhedral Structure.

\section{Introduction}

This document deals with what the SD (Sustainable Development) means and its measurement; then, based on a perspective of the DS based on the human being, its well-being and the satisfaction of its needs, to study the most adequate structure to face the problem posed by it.

To achieve the above, initially presents the evolution of the concept of SD and how it is understood as a polyhedral structure consisting of various elements whose understanding and development must be made from the interaction and harmonization of these.

In the second half of the XIX century, the British physicist and mathematician William Thomson Kelvin, expresses: "What is not defined cannot be measured. What is not measured cannot be improved. What is not improved is always degrades "; this is a sentence for the SD, since it condemns it to be part of a process of continuous improvement or to degrade over time, becoming an idea as romantic and abstract as trivial and inapplicable and dying in an ocean of good intentions without specifying. That is why the next topic to be treated in this document cannot be other than to present the reader with the problem of measuring SD.

Then, taking the human being as the core of the SD and turning their well-being into the

| ${ }^{1}$ PH.D. student in Sustainable Development. Industrial Engineer. Postgraduate in Production Engineering (Specialist); Master in Industrial Engineering (M.Sc.).

2PH.D. Professor and Researcher. Senior Researcher. Director of the Doctoral Program in Sustainable Development from the University of Manizales, Colombia. 
element that is the object of development and the life of this human being, but in conditions of welfare, as the element to sustain over time; a proposal of the structure is made with which the DS should be seen and approached. This structure aims to become the framework for the discussions and perspectives on the SD that are made, since without this framework any discussion will be diffuse, ambiguous and take the risk of remaining in something futile as the translation of "sustainability".

\section{What is Sustainable Development (SD)?}

Sustainable development is seen as a possibility of economic growth that is not detrimental to the conditions of an environment and in more extensive terms, this environment becomes the planet. But these conditions include dimensions that are in harmonic interrelation, since they are linked as parts of a whole or edges of a polyhedron, and correspond to the environmental, human, social, political, institutional, among others and that manifest themselves as resulting from different combinations of states, induced or natural.

The SD come from the evolution of initiatives that pursued the protection of the environment, the regulation of the human-nature relationship and to maintain the progress and development of human society without affecting economic growth. The terms "Development" and "sustainability" began to be used as part of the same sentence, as a result of a study commissioned by the Club of Rome to the MIT (Massachusetts Institute of Technology) in 1970 and which was known as the Meadows report. and published under the title The Limits to Growth (Meadows, 1972). This study is where, at first time, the idea of a limit to the growth and consumption of the planet's resources is presented, as they are presented as finite and this is done under the premise that sustained economic growth on a finite planet it would lead us to collapse and that to avoid it, it is necessary to put limits on demographic growth, industrialization and the exploitation of "natural resources" (Soto-Torres, 2012).

In the World Conservation Strategy of the International Union for the Conservation of Nature, published in 1980, the concept of sustainable development and global dependence on nature and development was highlighted. Sustainable development was defined as the modification of the biosphere and the use of living and non-living financial human resources to improve the needs and quality of life of human beings, taking into account social, ecological and economic factors. (Brunold, 2004)

Subsequently, in 1983, the World Commission on Environment and Development was created, which published in 1987 the Brundtland report also known as "Our Common Future", in which the term "Sustainable Development" is used for the first time. "And this is defined as "meets the needs of the present without compromising the ability of future generations to meet their own needs" (Brundtland, 1987: 23). This definition includes the demand of contemporary and future generations, natural resources, ecological carrying capacity, the combination of environment and development. In this context, "Sustainable Development" consists of a scheme of human, social and economic development that is capable of remaining indefinitely in harmony with the biophysical systems of the planet (Schuschny \& Soto, 2009).

Afterwards, the exercise of giving shape to the different structures derived from the 
conceptualizations of SD is initiated in order to achieve a greater understanding of their behavior, overall, to be able to understand and locate the origin of the SD and its elements. This is the case when, at the Gothenburg European Council in 2001, its president, Nicole Fontaine, presented the first conceptions of a structure made up of what she called economic, social and environmental dimensions; giving them the indivisible character (Artaraz, 2001).

In the same line Durán, Gogan, Artene and Duran (2015), show three (3) key components of the SD, identifying them as the economic component, the ecological component and the human component. Adding that development should be conceived as a multidimensional process, involving fundamental changes in social structures, in institutions, aiming at accelerated economic growth, reducing inequality and eradicating poverty (Duran, Gogan, Artene, \& Duran, 2015).

Is from the complexity of each of the dimensions of the SD and the interrelation of these, this can be seen as the harmony (or harmonization) between multiple forces that interact permanently with the different biophysical systems of the planet and economic growth. This harmony can be understood when we see between the lines on the conditions that development must have when it is argued that it must be economically efficient, ecologically sustainable, socially equitable, democratically founded, geopolitically acceptable, culturally diversified (Gómez Contreras, 2014). And what makes this development problem and its sustainability should be approached from a broader perspective than just the environmental one, implies an approach from the human, the social, the political, the institutional and the economic, as structural edges of a polyhedron.

\section{The Problem of Measuring the SD}

In the second half of the XIX century, the British physicist and mathematician Sir William Thomson First Baron of Kelvin, expresses: "What is not defined cannot be measured. What is not measured cannot be improved. What is not improved, is always degraded ", This expression was installed as a paradigm for measuring all those processes that, inherently or accidentally, have continuous improvement as one of their basic characteristics for decision making and achieve desired objectives or goals.

The measurement of sustainable development has become a real challenge, on the one hand because its measurement must be structured by a set of elements related to the different dimensions involved and this structure, in turn, must be adopted as a tool relevant in public development policies; On the other hand, we must add the complexity and multidimensionality of the development processes (Landerretche, Leiva, Vivanco, \& López, 2017).

It is essential, in order to understand, measure and evaluate the DS, to understand that: an individual or universal structure can never be induced from the study of isolated elements, just as we cannot know the typical physiognomy of a particular human race studying in some separated eyes, mouth, nose, etc., without ever seeing their network of relationships together (Martínez Miguélez, 2006). It is this relationships networks that defines the behavior of the SD, the projections made of it and the possible levels of response that in its different dimensions are given, product of its incessant dynamics. 
The SD approach must be done as a whole, that is, in the systemic context, as the result of the interaction of the parts or subsystems that integrate it, give it form and allow it to reach its objective or function.

In a simple way, but complete, this had already been expressed by Blas Pascal:

"...Being, then, all things caused and causing, aided and assisted, mediate and immediate, and all maintained by a natural and insensitive nexus linking the most remote and the most different, I have no way of knowing the parts without knowing the whole, as well how to know the whole without knowing particularly more parts" (Pascal, Thoughts, 1669: 72).

This permanent dynamism, product of the continuous interaction with the environment, of the interrelation of its integrating structures and dimensions and of the definitive participation of the human being as an active element of the SD, reason of the changes between the interactions and interrelationships and, at the same time, passive object of the different results of these processes; makes the complexity of this system is high and that the understanding of it, based on unawareness or assumptions of the relationships between the variables that make up its dimensions, is unsustainable, away from reality.

On the other hand, the study of the interaction between environmental systems and those generated by anthropic action gives rise to high levels of ambiguity as well as the incorporation of subjectivity as an element to be taken into account, which generate an additional component of uncertainty (Schuschny \& Soto, 2009).

It is this mixture of elements such as complexity, variability, multidimensionality and the interactions between the dimensions of SD and natural biophysical systems and those that have their origin in anthropic actions, mentioned by Landerretche (2017), Martinez (2011), Schuschnny (2009), Arnold (1998), Hall (1956), among others; In what is understood as SD, it makes the problem of measuring in an objective manner, if we approach or move away from a goal or objective, extremely difficult.

Given this scenario, the question arises: How can the SD be measured? As it is obvious and taking the first part of the sentence of William Thomson Kelvin, we must begin with the definition of DS. Aguilar-Barajas (2002) cites the Organization for Economic Cooperation and Development (OECD): "On the surface there is agreement: sustainable development refers to several issues that go beyond the relationship between economy and environment to include human concerns and social. By scratching the surface, a Pandora's box of different notions of sustainability and ways to reach it is opened "(Aguilar-Barajas, 2002: 98).

Here a new element of the problem appears. Some authors such as Gracia-Rojas (2015), Cantú-Martinez (2013), Velayos-Castelo (2008), Cantú-Martinez (2008), Vega-Marcote (2007), Gutierrez (2007), Smounts (2005), Harribey (1998), Vivien (2005), Sarandon (1998), Bejarano-Avila (1998), Naredo (1996), Passet (1996), Angel-Maya (1995), among others, affirm that the concept of SD is abstract, too general or even contradictory. Sarandon (2000) says that "justly, sustainability is one of those terms that owe their wide acceptance, to their ambiguity. Everyone agrees to reach it, but nobody knows what it is about. And, therefore, you cannot measure progress or setbacks "(Sarandón, 2002: 393). This has generated the indiscriminate, excessive and widespread use of the sustainable epithet in socio-economic-environmental literature which, as Naredo (1996) says, can be inscribed within those fashion terms used by the social sciences, precisely because its 
ambiguity leads to using them more as spells than as useful concepts in understanding and solving problems (Naredo, 1996).

The consequence of such ambiguity in the concept of SD, has been that this is a concept on which there is still no consensus and that after almost 50 years of having seen the light, it is still under construction. And the risk of such dispersion of interpretations is the sustainability: that everything pretends to be passed by sustainable (Velayos-Castelo, 2008).

Then comes the discussion about what is the element that wants to sustain over time, and this depends directly on the definition of SD that is addressed and on which, there is still no consensus. The result is that there can be as many elements to sustain as SD definitions and even, the abstraction of the concept, can lead to multiple elements to be supported, or none or one as abstract as the definition itself from which it arises. As Loukola and Skyllönen (2005) say, the way in which sustainability is conceptualized is constantly changing, along with the changes presented by circumstances or context (Loukola \& Kyllönen, 2005).

Some of the elements to sustain in time that are identified by different authors are natural resources (Carpenter, 1991); sustain consumption levels (Redclift, 1987); achieve the sustainability of all resources: human capital, physical capital, environmental resources, exhaustible resources (Bojo et al., 1990); pursue the integrity of the processes, cycles and rhythms of nature (Shiva, 1989); the quality of life, the capacity of natural resources to provide economic growth, biodiversity (Artaraz, 2001), among other examples and which, as Rayén says, becomes the central node of this discussion (Rayén Q., 2001).

Regardless of which element is determined as an object to sustain, it is necessary to have clear the following questions: Why should it be sustained over time? How should it be sustained? And for how long would it be necessary to sustain it? Despite this, it is clear that while there is no specific framework, any discussion will be diffuse, ambiguous and runs the risk of remaining in something futile as the translation of "sustainability".

\section{Well-Being and Sustainable Development}

The satisfaction of the needs of the human being leads to what is known as wellbeing, which has been studied and defined by various authors throughout the history of humanity itself. Likewise, the different economic models that humanity has implemented, associate welfare with economic growth and these in turn with happiness. This senseless association, based on the intensive consumption of resources that can be transformed into wealth and transitivity into wellbeing and happiness, has led to predatory behavior that sees its effects in social, human, territorial and environmental conflicts, fundamentally.

In order to understand how the human being conceives the satisfaction of their needs and well-being that this produces, the two (2) most thinking schools of thought around this concept will be taken as a base: Hedonic School and Eudaimonic School.

The hedonic school of thought sees well-being mainly as the maximization of pleasure (and minimization of pain) (Thompson and Marks, 2008, Dolan et al., 2006). In contrast, the eudaimonic school of thought sees well-being as the ability of humans to reach their 
maximum potential within the context of their society. It is fair to say that the hedonic school is dominant in multiple scenarios and spheres (Brand-Correa \& Steinberger, 2017).

As the modern economy was developed based on consumption and the generation of capital, a utility model was created and massifying based on potentially infinite and insatiable individual desires. Therefore, the maximization of utility was very strongly associated with the satisfaction of the needs of the individual.

As it is understood, hedonism has clear consequences for sustainability: any limitation for levels of consumption or generation of capital can be immediately perceived as limits to well-being. Similarly, in a hedonic world, intergenerational factors cannot be considered in assessing well-being, since it is a static assessment of the particular experience (s) of an individual. This is especially relevant for environmental and climatic considerations, in which current actions inevitably have future impacts (Brand-Correa et al., 2017).

In contrast, eudaimonic well-being focuses on the individual in the broader context of their society. Therefore, a eudaimonic understanding of well-being is more appropriate to address sustainability issues. A similar argument can be made about the importance of intergenerational responsibilities in long-term sustainability. An eudaimonic vision of well-being allows the inclusion in the analysis of a sense of social belonging to our community both in the past and in the future, thus opening the space for intergenerational citizenship through the exchange of projects and common places (Chica \& Benavides, 2018).

Well-being, within the framework of SD, must be seen with an eudaimonic conception in which social development and individual development cannot occur in a divorced manner. As he says (Max-Neef, Elizalde, \& Hopenhayn, 1986), when they talk about the articulation between the personal and the social "A healthy society must consider, as an unavoidable objective, the joint development of all people and the whole person" (p.35).

\section{Harmonic Polyhedral Conception of the SD}

Sustainable Development can be seen as the harmony (or harmonization) between forces composed of the different biophysical systems of the planet, the human social systems and by the development seen as economic growth. This approach leads to it being conceived as a harmonic polyhedron whose lateral edges are formed by four structures formed by an equal number of dimensions are identified, building the DS as a polyhedron. These structures are: The Socio-Humanistic Dimension, the Economic Dimension, the Institutional Dimension and the Environmental Dimension.

Each dimension have a triangular composition whose basis is life of all the beings that participate or are directly or indirectly affected by the growth, contraction, expansion, improvement and other possible outcomes of the movements or variations of these and, particularly, the human species; and the planes formed by their edges, which are the interactions between them, as previously written, a lateral edge that corresponds to the human needs associated with that dimension, as an element to be solved and on which the "capacities" offered by the product are observed. improvement, and the other edge is associated to the characteristic to develop of each dimension (Figure 1). 

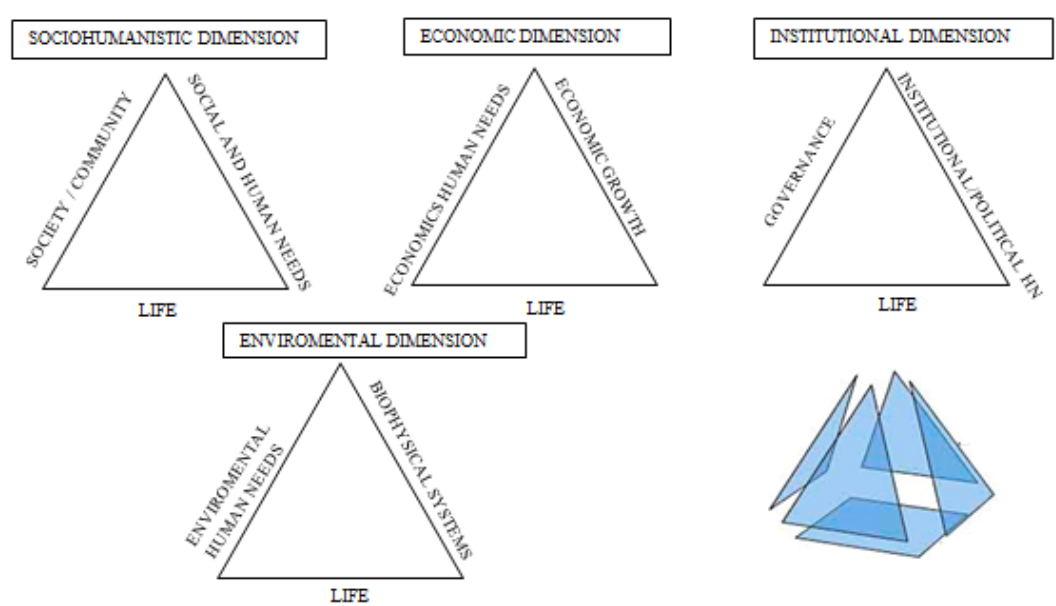

Figure 1. Dimension and polyhedral structure of $S D$

Thus, as when each of these structures begin to be integrated to build the harmonic polyhedron of the DS, that new structures resulting from the interactions of the edges begin to form, in the following way:

The structure of the Sociohumanistic Dimension joins with the structure of the Economic Dimension. This union is made through the edges of human needs, which, when merged, give rise to an internal plane called Plane of Human Socioeconomic Needs. This internal plane extends to the core of the polyhedron and becomes the key to the conformation of the nucleus or main axis of the polyhedral structure of the DS, as it constitutes the first hemiplane of human needs (figure 2).

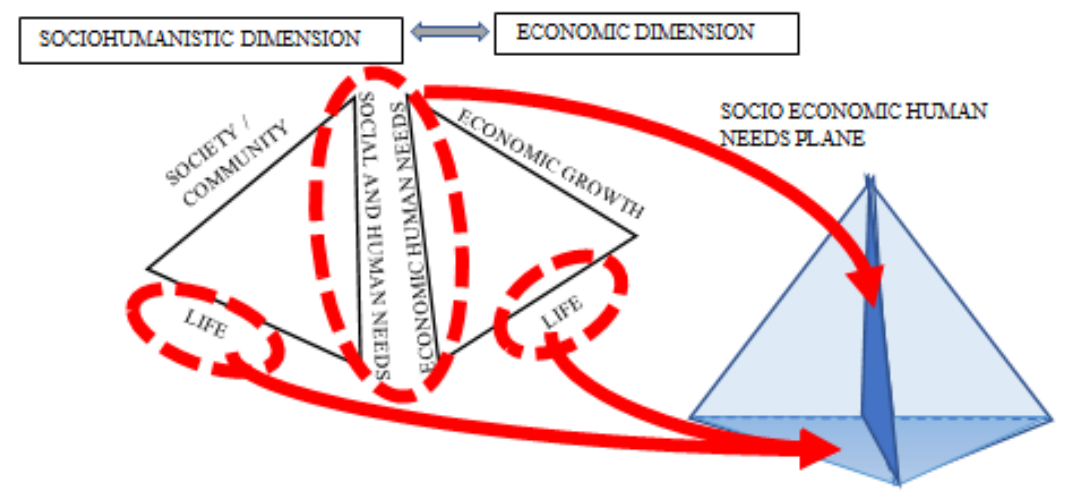

Figure 2. Join between Sociobumanistic Dimension and Economic Dimension

In turn, the structure of the Economic Dimension joins the structure of the Institutional Dimension. This union is made through the edges of Economic Growth and Governance, which merge give rise to an internal plan called Legal Framework (legal, political and regulatory) for economic growth and institutional and political support. This internal plane extends to the center of the polyhedron and becomes a key for the conformation of the nucleus or main axis of the polyhedral structure of the DS (figure 3). 


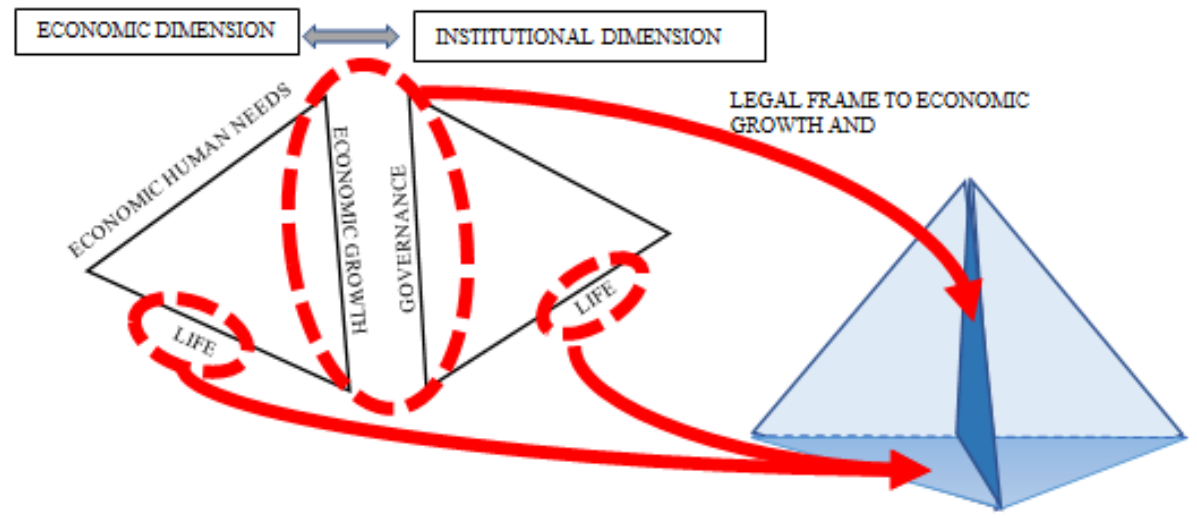

Figure 3. Join between Economic Dimension and Institutional Dimension

For its part, the structure of the structure of the Institutional Dimension is linked to the structure of the Environmental Dimension. This union is made through the edges of Institutional / Political Human Needs and Human Environmental Needs, which merge give rise to an internal plane called Plane Human Environmental, Institutional, Legal and Political Needs. This internal plane extends to the center of the polyhedron and becomes the key to the conformation of the nucleus or main axis of the polyhedral structure of the DS, as it becomes the second hemiplane of human needs (figure 4).

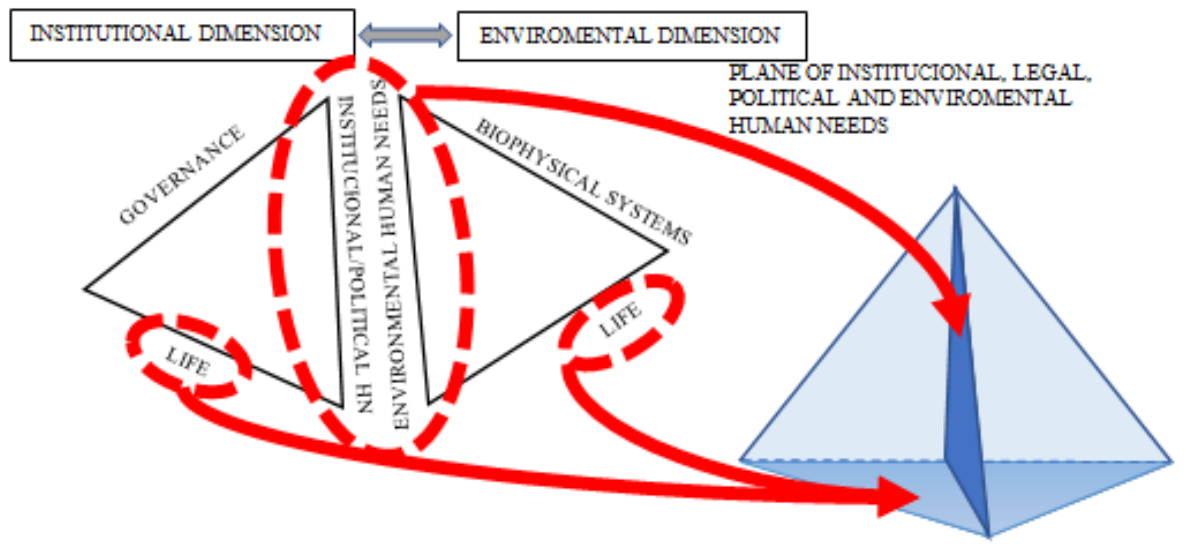

Figure 4. Join between Institutional Dimension and Environmental Dimension

To complete the outer and inner part of the polyhedron, the structure of the Environmental Dimension joins the structure of the Social Dimension. This union is made through the edges of the Biophysical Systems and Society / Community, which merge give rise to an internal plane called Ecological Plan, since it is formed from the interaction of biophysical systems with the social systems, represented by society / community. This internal plane extends to the center of the polyhedron and becomes a key for the conformation of the nucleus or main axis of the polyhedral structure of the $\mathrm{SD}$ (figure 5) 


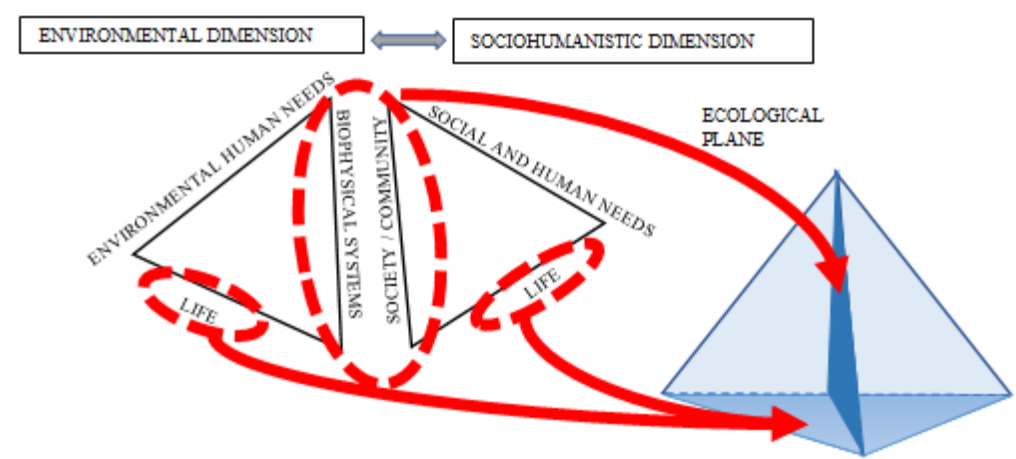

Figure 5. Join between Environmental Dimension and Sociobumanistic Dimension

To finish the polyhedral structure are the two main elements: The base and the core or central axis (Figure 6). The base is the plane formed by the union of all the base edges of the dimensions, which had already been defined, correspond to the life of all the beings that participate or are directly and indirectly affected by growth, contraction, expansion, improvement and other possible resulting movements or variations of these and, particularly, the human species. When merged, all these edges, in a single plane, group all the manifestations of life of all the related species, linked, participating or affected directly and indirectly by the SD. This basic plan is fundamental because, in addition to dealing with the materialization of life as the origin and sustenance of SD, it also becomes the solution to the problem of what element to sustain? while, with its expansion, performs the task of intragenerational integration, that is, linking more individuals of the same generation.

The core or central axis of the formed polyhedron is the structure in which, with its root at the base of the polyhedron, the four internal planes formed by the union of the edges of the dimensions of the SD are braided. That is to say that in this element human needs are woven with the capacities and satisfiers that satisfy them. This axis is fundamental, because its longitudinal growth implies intra-generational integration, that is, it projects the SD to the new generations and satisfies their needs; while its transversal growth implies the linking of a greater quantity of human needs, satisfiers and capacities to the quality of life. That is to say, that the transversal and longitudinal growth of this axis, leads to well-being as an answer to the questions of why to sustain it? And how to sustain it?

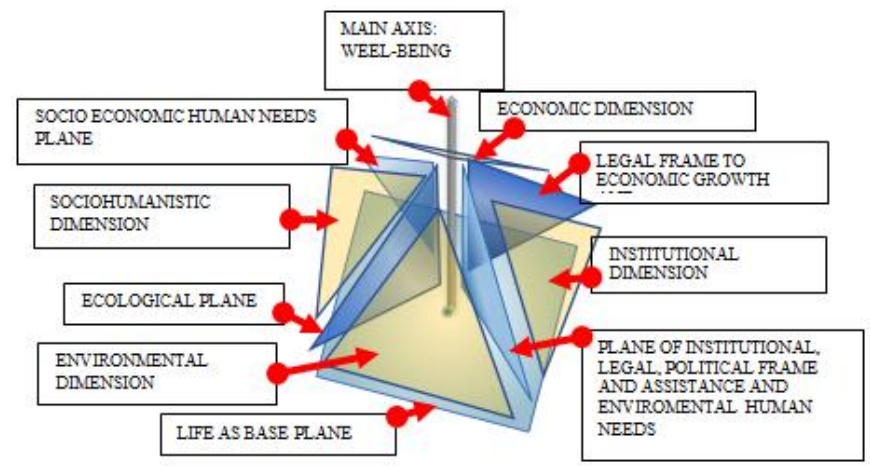

Figure 6. External and Internal structure form SD as a Harmonic Polyhedron. 
Now, as mentioned before, both the main or base plan and the fundamental or improvement axis are associated with life and well-being, which implies that there is a fundamental relationship between SD and Well-being, which is why must be seen from the eudaimonic perspective, in which this is observed as the ability of individuals to reach their maximum potential within their social context or society. Perspective this, which makes the relationship between the development of the individual and social development indissoluble.

\section{Conclusions}

The relationship between biophysical, human and economic systems has been observed since when human beings began to modify their environment in order to subsist while improving their living conditions. This behavior was accentuated and as it grew, began to observe that the rate of consumption of resources was greater than the rate of regeneration of the same and the capacity of absorption of waste by the planet. This results in the consideration that we are on a planet whose resources are finite and our way of exploiting them is not consistent with this reflection. From there arises the debate for Sustainable Development, which is observed initially as a development that allows an interaction between biophysical and economic systems that meets the needs of growth while being consistent with natural limits.

Since the 70 s of the last century, different conceptions of the elements "development" and "sustainability" have been conjugated, which has caused the SD to be seen as a problem from these elements, since their different conceptions They can be as broad, abstract and ambiguous as complex and, above all, immeasurable. This has brought the following consequences:

That there are countless forms, models and methodologies of evaluation and measurement of SD, which depend on the concepts of development and sustainability and the elements to be developed and sustained. The effects of the above are not other than the heterogeneity in the SD measures and values; the difficulty in reproducing the measurement in different contexts, territories or moments; the presence of innumerable "Rankings" of DS whose objective is to classify territories or initiatives and that generate confusion, bias and disinformation.

That the SD is not seen as an integrated system where different dimensions interact and interrelate, but as a group of isolated dimensions that intersect in common points and whose initiatives do not necessarily have to be integral.

That the terms "Sustainable Development" and "Sustainability" or "Sustainability" are used indiscriminately and excessively, which leads to the trivialization of them and the loss of their significance.

That is why the SD must be seen under a new perspective, that of an integral structure made up of four (4) basic dimensions of sustainable development, namely: Social Dimension, Economic Dimension, Environmental Dimension and Institutional Dimension; and based on life and well-being, the latter being approached from the eudaimonic perspective under which Social Development and Individual Development cannot happen in a divorced way.

It is only under this new integrating, harmonious and structured perspective that we can 
put an end to this phenomenon characterized by putting the name of "sustainable" to almost anything and calling, in the same way, "DS" to any initiative, since these they would be obliged to impact the different edges of the polyhedron, either directly or through the interactions between planes, and reflect results in the improvement of the living conditions and well-being of people and in general of life associated with SD.

\section{References}

Aguilar-Barajas, I. (2002). Reflections on sustainable development. Foreign Trade, 52 (2), 98-105.

Artaraz, M. (2001). Theory of the three dimensions of sustainable development. Ecosystems, X (3), 1-6. https://doi.org/10.7818/RE.2014.11-2.00

Brand-Correa, L. I., \& Steinberger, J. K. (2017). A Framework for Decoupling Human Need Satisfaction From Energy Use. Ecological Economics, 141, 43-52. https://doi.org/10.1016/j.ecolecon.2017.05.019

Brundtland, G. H. (1987). Our Common Future: Report of the World Commission on Environment and Development. United Nations Commission, 4(1), 300. https://doi.org/10.1080/07488008808408783

Brunold, A. O. (2004). La Agenda 21 y las perspectivas de cooperacion Norte-Sur. El principio del desarrollo sostenible, 11(4), 299-308.

Chica Urzola, J. A., \& Benavides Miranda, V. (2018). Sustainable Development, Human Needs , Well-Being and Energy. International Journal of Innovation and Research in Education Sciences - IJIRES -, 5(1), 52-56. Retrieved from https://www.ijires.org/administrator/components/com_jresearch/files /publications/IJIRES_1182_FINAL.pdf

Duran, D. C., Gogan, L. M., Artene, A., \& Duran, V. (2015). The Components of Sustainable Development - A Possible Approach. Procedia Economics and Finance, 26(15), 806-811. https://doi.org/10.1016/S2212-5671(15)00849-7

Gómez Contreras, J. L. (2014). From sustainable development to environmental sustainability. Magazine Faculty of Economic Sciences Research and Reflection, 22 (1), 115-136.

Landerretche, O., Leiva, B., Vivanco, D., \& López, I. (2017). Welcoming uncertainty: A probabilistic approach to measure sustainability. Ecological Indicators, 72, 586-596. https://doi.org/10.1016/j.ecolind.2016.08.050

Loukola, O., \& Kyllönen, S. (2005). Philosophies of sustainability. Sustainable Use of Renewable Natural Resources: From Principles to Practices, 3, 15-21.

Martínez Miguélez, M. (2006). General Scientific Knowledge and Ordinary Knowledge. Redalyc.Org, (27), 1 10. Retrieved from http://www.revistas.uchile.cl/index.php/CDM/article/viewFile/25937/27250

Max-Neef, M., Elizalde, A., \& Hopenhayn, M. (1986). Development on a human scale: options for the future. Library CF + S, 56. https://doi.org/10.1080/10584600802686105

Meadows, D. H. M. (1972). The Limits to Growth. The Club of Rome, 211. https://doi.org/10.1111/j.17521688.1972.tb05230.x

Naredo, J. M. (1996). On the origin, use and content of the term "sustainable." Cuadernos de Investigación Urbanistica, 41, 48-57.

Pascal, B. (1669). Thoughts. (E. del Cardo, Ed.). Biblioteca Virtual Universal. Retrieved from http://www.biblioteca.org.ar/libros/89354.pdf

Rayén Q., M. (2001). Indicators of environmental sustainability and sustainable development: state of the art and perspectives. SERIES Manuals (Vol. 16). Retrieved from http://hdl.handle.net/11362/5570

Sarandón, S. J. (2002). The development and use of indicators to evaluate the sustainability of agroecosystems. Agroecology: The Road to Sustainable Agriculture, 393-414. Retrieved from http://wp.ufpel.edu.br/consagro/files/2010/10/SARANDON-cap-20-Sustentabilidad.pdf

Schuschny, A., \& Soto, H. (2009). Methodological guide Design of composite indicators of sustainable development. Cepal - UN, 109. https://doi.org/LC/W255

Soto-Torres, G. (2012). Sustainable Development or Environmental Ethics. Articles and Essays on Rural Sociology, 13 (January-June 2012), 6-19.

Velayos-Castelo, C. (2008). What sustainability ?: a reading from Practical Philosophy. Roles of Ecosocial Relations and Global Change, 101, 13-26. Retrieved from http://www.fuhem.es/media/ecosocial/file/Sustainability/Economy Economics / Que_sostenibilidad_CarmenVelayos.pdf 